HEPATOLOGY

\title{
Cloning and expression profile of FLT3 gene during progenitor cell-dependent liver regeneration
}

\author{
Iraz T Aydin,* Zeynep Tokcaer, ${ }^{*}$ Aydin Dalgic, ${ }^{\dagger}$ Ozlen Konu* and Kamil C Akcali* \\ *Department of Molecular Biology and Genetics, Bilkent University, and 'Department of Surgery, Gazi University Medical School, Ankara, Turkey
}

\author{
Key words \\ cloning, FLT3, liver regeneration, rat. \\ Accepted for publication 15 July 2006. \\ Correspondence \\ Dr Kamil C Akcali, Department of Molecular \\ Biology and Genetics, Bilkent University, \\ Bilkent, Ankara 06800, Turkey. Email: \\ akcali@fen.bilkent.edu.tr
}

\begin{abstract}
Background and Aim: The liver has a unique capacity to regenerate upon exposure to viral infections, toxic reactions and cancer formation. Liver regeneration is a complex phenomenon in which several factors participate during its onset. Cellular proliferation is an important component of this process and the factors that regulate this proliferation have a vital role. FLT3, a well-known hematopoietic stem cell and hepatic lineage surface marker, is involved in proliferative events of hematopoietic stem cells. However, its contribution to liver regeneration is not known. Therefore, the aim of this study was to clone and examine the role of FLT3 during liver regeneration in rats.

Methods: Partial cDNA of rat homolog of FLT3 gene was cloned from thymus and the tissue specific expression of this gene at mRNA and protein levels was examined by RT-PCR and Western blot. After treating with 2-AAF and performing hepatectomy in rats to induce progenitor-dependent liver regeneration, the mRNA and protein expression profile of FLT3 was investigated by real-time PCR and Western blot during liver regeneration. In addition, cellular localization of FLT3 protein was determined by immunohistochemistry.

Results: The results indicated that rat FLT3 cDNA has high homology with mouse and human FLT3 cDNA. It was also found that FLT3 is expressed in most of the rat tissues and during liver regeneration. In addition, its intracellular localization is altered during the late stages of liver regeneration.

Conclusion: The FLT3 receptor is activated at the late stages of liver regeneration and participates in the proliferation response that is observed during progenitor-dependent liver regeneration.
\end{abstract}

\section{Introduction}

The liver has a great capacity to regenerate after the loss of hepatocytes by toxic or viral injury or secondary to liver resection ${ }^{1,2}$ with a process known as liver regeneration, as illustrated by the ancient Greek legend of Prometheus. Liver regeneration is a complex physiological response, and a series of reactions must take place for survival of the organism. Oval cells have a central role in progenitor-dependent liver regeneration and they are activated to proliferate when the replication and functional capacity of the mature hepatocytes is disrupted. ${ }^{3,4}$ Oval cells are regarded as bipotential precursors for the two hepatic parenchymal cell lineages, hepatocytes and bile duct cells, and have lineage options similar to those displayed by hepatoblasts in early stages of liver development. ${ }^{5-8}$ Several models in rodents have been established for triggering oval cell proliferation. ${ }^{9}$ In the model of 2-acetaminofluorene (2-AAF) treatment and partial hepatectomy (PH) operation (2-AAF/PH), the proliferating oval cells form irregular duct-like structures that are connected with preexisting bile ducts. ${ }^{10}$ The continuous administration of a low concentration of 2-AAF suppresses the proliferation of hepatocytes and at the middle point of the treatment the animals are subjected to a massive loss of hepatocytes by $\mathrm{PH}$. When the hepatocytes do not respond to growth signals, there is rapid growth of the oval cells. ${ }^{11}$

Oval cells express specific proteins, one of which is thought to be FLT3. ${ }^{12-14}$ FLT3 encodes an receptor tyrosine kinase (RTK) of 993 amino acids that belongs to the RTK subclass III family and is a well-known hematopoietic stem cell marker. ${ }^{15,16}$ Unstimulated FLT3 receptors are in monomeric form in the plasma membrane. In this inactive state, the conformation of the receptor might result in steric inhibition of dimerization and exposure of phosphoryl acceptor sites in the tyrosine kinase domain (TKD) by the juxtamembrane domain. ${ }^{16}$ After stimulation with the ligand FLT3L, membrane-bound FLT3 quickly changes conformation, and forms a homodimer and exposes phosphoryl acceptor sites in TKD. ${ }^{17}$ Dimerization stabilizes this conformational change, which further enhances activation of the receptor. ${ }^{18}$ The rate of FLT3 production, the speed of degradation of the activated FLT3L-FLT3 complex, 


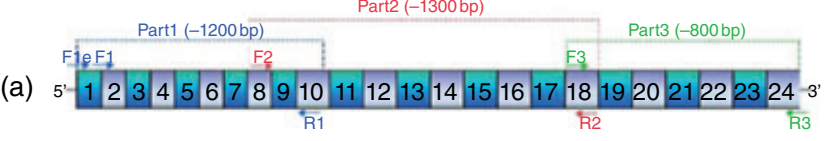

(b)

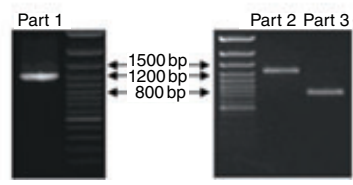

Figure 1 (a) Exons of FLT3 and location of cloning primers. F1e-F1 and R1 primers (blue) were used for amplifying Part 1, F2 and R2 primers (red) were used for amplifying Part 2, and F3 and R3 primers (green) were used for amplifying Part 3. (b) Agarose gel electrophoresis of PCR products of Part 1, Part 2 and Part 3. All three fragments were amplified from thymus cDNA. 100 bp DNA Ladder Plus was used as the molecular size marker.

and the downstream effects of activation probably participate in a complex feedback loop that regulates normal receptor activity. ${ }^{16} \mathrm{~A}$ recent study also suggests that FLT3 is a hepatic lineage surface marker. ${ }^{19}$ Its existence in oval cells further supports its crucial role in hepatocyte development. However, the expression pattern of FLT3 has not been investigated during liver regeneration.

Previously, our research team has examined the involvement of the bcl-2 family of genes during liver regeneration, ${ }^{20}$ as proliferative and apoptotic mechanisms operate to provide a balance for the survival. In this study we focused on the other aspect of this complex process; proliferative response. We aimed to monitor the expression of FLT3 at both mRNA and protein levels, in progenitor cell-dependent liver regeneration. Other than the elucidation the role of FLT3 in the proliferative response, we also aimed to isolate and sequence the cDNA of rat FLT3 and monitor its tissue specific expression.

\section{Methods}

\section{Cloning of rat FLT3}

The cDNA sequences of mouse FLT3 (NM 010229), human FLT3 (NM 004119), and predicted rat FLT3 (XM 221874) were aligned using ClustalW tool (European Bioinformatics Institute; http:// www.ebi.ac.uk/clustalw/). We aimed to clone the full-length FLT3 cDNA in three overlapping fragments. The primers were designed for the regions conserved among three species. The locations and sequences of the cloning primers are shown in Fig. 1a and in Table 1, respectively. Total cDNA from rat thymus was used as template with the following PCR conditions: the initial denaturation step at $95^{\circ} \mathrm{C}$, followed by 45 cycles of denaturation for $60 \mathrm{~s}$ at $94^{\circ} \mathrm{C}$, annealing for $60 \mathrm{~s}$ at $55^{\circ} \mathrm{C}$ and extension for $60 \mathrm{~s}$ at $72^{\circ} \mathrm{C}$. A final extension at $72^{\circ} \mathrm{C}$ for $10 \mathrm{~min}$ was applied to all the reactions. PCR products were electrophoresed and sequenced.

\section{Animals}

Male 9-week-old, 280-300 g Sprague-Dawley rats were used. They were housed under controlled environmental conditions
Table 1 Primers used for cloning of rat FLT3

\begin{tabular}{ll}
\hline Primer & Sequence \\
\hline F1e & 5'-TCT AGA ATG CGG GCG TTG CG-3' \\
F1 & 5'-CTG CTT GTT GTT TTG TCA GTA ATG-3' \\
R1 & 5'-GGT TGT TCT TAT GAT CGC AAA ATT-3' \\
F2 & 5'-ACA GCG TTG GTG ACC ATC CTA-3' \\
R2 & 5'-GAA TTG AAT TCC CAT TGA ACC CTG-3' \\
F3 & 5'-GTT CAA TGG GAA TTC AAT TCA TTC-3' \\
R3 & 5'-TCT AGA CTA ACT TTT CTC TGT GAG-3' \\
\hline
\end{tabular}

$\left(22^{\circ} \mathrm{C}\right)$ with a 12 -h light-dark cycle in the animal holding facility of the Department of Molecular Biology and Genetics at the Bilkent University. All the animals received care according to the criteria outlined in the 'Guide for Care and Use of Laboratory Animals' prepared by the National Academy of Science, and this study protocol complied with Bilkent University's guidelines on humane care and use of laboratory animals. The animals were permitted unlimited access to food and water at all times.

\section{Experimental groups}

A 2-AAF solution $(125 \mathrm{mg} / \mathrm{mL})$ was prepared in DMSO, then $50 \mathrm{mg} / \mathrm{kg}$ 2-AAF was administrated to each rat for 6 days. On the seventh day, liver surgery was performed after injecting ketamine (Ketalar, Pfizer, Istanbul, Turkey) subcutaneously at a dose of $30 \mathrm{mg} / \mathrm{kg}$. In the partial hepatectomy $(\mathrm{PH})$ group $70 \%$ of the liver mass was resected, ${ }^{21}$ and in the sham hepatectomy $(\mathrm{SH})$ group the same surgical procedures were carried out but the liver lobes were not resected. Operations were performed between 08:00 and 12:00 hours to minimize diurnal effects. After completion of the procedure, the animals were placed under a lamp to prevent hypothermia and then put into cages (one animal per cage) with continuous supply of food and water.

Three randomly selected animals from the $\mathrm{PH}$ and $\mathrm{SH}$ groups were killed by cervical dislocation at $2 \mathrm{~h}, 12 \mathrm{~h}, 18 \mathrm{~h}, 24 \mathrm{~h}$ and 7 days after the operation. The remnant liver lobes were excised and washed in DMEM medium, then immediately frozen in liquid nitrogen.

\section{Total RNA isolation and reverse transcription}

Total RNA was isolated from tissue samples using Tripure solution (Roche-Boehringer Mannheim, Germany) according to the manufacturer's protocol. The integrity of the isolated RNA samples was determined by denaturing- (formaldehyde-) agarose gel electrophoresis. The cDNA samples were synthesized from the total RNA samples with the RevertAid First Strand cDNA Synthesis Kit (Fermentas, Burlington, ON, Canada) according to the manufacturer's protocol.

\section{Real-time RT-PCR}

The primers that were used for real-time RT-PCR are shown in Table 2. Before performing the real-time RT-PCR reactions for experimental samples, the amplification efficiencies of FLT3 and cyclophilin (CYC; internal control) primers were calculated using a standard dilution series. The initial denaturation step was at $95^{\circ} \mathrm{C}$ 
Table 2 Primers used for real-time RT-PCR

\begin{tabular}{ll}
\hline Primer & Sequence \\
\hline FLT3 Forward & 5'-TGG TGA CCT GCT CAA CTA CCT A-3' \\
FLT3 Reverse & 5'-AGT CAC AGA TCT TCA CCA CCT T-3' \\
CYC Forward & 5'-GGG AAG GTG AAA GAA GGC AT-3' \\
CYC Reverse & 5'-GAG AGC AGA GAT TAC AGG GT-3' \\
\hline
\end{tabular}

for $10 \mathrm{~min}$, followed by 50 (for FLT3) and 32 (for CYC) cycles of denaturation for $60 \mathrm{~s}$ for FLT3 and $30 \mathrm{~s}$ for $\mathrm{CYC}$ at $94^{\circ} \mathrm{C}$, annealing for $60 \mathrm{~s}$ at $60^{\circ} \mathrm{C}$ for FLT3 and $30 \mathrm{~s}$ at $55^{\circ} \mathrm{C}$ for $\mathrm{CYC}$ and extension for $60 \mathrm{~s}$ for FLT3 and $30 \mathrm{~s}$ for $\mathrm{CYC}$ at $72^{\circ} \mathrm{C}$. A final extension at $72^{\circ} \mathrm{C}$ for $10 \mathrm{~min}$ was applied to all the reactions. The real-time PCR reactions followed by a melting curve analysis were carried out in iCycler (Bio-Rad, Hercules, CA, USA). The threshold cycle $(\mathrm{Ct})$ values for FLT3 and CYC for each of the 2-AAFtreated SH and PH samples (normal liver, 0 h, 2 h, 12 h, 18 h, 24 h and 7 days) were obtained. Fold change in the expression of FLT3 was estimated based on the comparative $\mathrm{Ct}\left(2^{-\Delta \Delta \mathrm{Ct}}\right)$ method $^{22}$ using the normal liver sample as calibrator.

\section{Protein isolation and quantification}

For protein isolation, $100 \mathrm{mg}$ of tissue samples were homogenized in $1 \mathrm{~mL}$ of Camiolo Buffer and centrifuged at $12000 \mathrm{~g}$ for $20 \mathrm{~min}$ at $4^{\circ} \mathrm{C}$. In order to check the equal loading, $12 \mu \mathrm{g}$ of protein samples were run on $8 \%$ sodium dodecyl sulfate-polyacrylamide gel electrophoresis (SDS-PAGE). A $5 \mu \mathrm{L}$ PageRuler Prestained Protein Ladder (Fermentas) was used as protein molecular weight marker. After electrophoresis, the gel was stained with Coomassie staining solution for $5 \mathrm{~min}$ and then destained with Coomassie destaining solution overnight.

\section{Western blotting}

The proteins were separated on $8 \%$ SDS-PAGE and transferred to polyvinylidene fluoride membrane. The membrane was blocked with blocking solution for $1 \mathrm{~h}$ at room temperature. FLT3 antibody (Santa Cruz Biotechnology, Santa Cruz, CA, USA) was diluted to a concentration of $0.2 \mu \mathrm{g} / \mathrm{mL}$ in blocking solution, and the membrane was incubated in antibody solution for $1 \mathrm{~h}$ at room temperature. Then, the membrane was incubated in 1/5000 diluted antirabbit-horseradish peroxidase (HRP; Sigma, St Louis, MO, USA) secondary antibody solution for $1 \mathrm{~h}$ at room temperature. Finally, the membrane was incubated with ECL Plus Detection Reagent (Amersham Biosciences, Piscataway, NJ, USA) for $5 \mathrm{~min}$ and placed in a X-ray film cassette and developed.

\section{Immunohistochemistry}

Paraffin sections (5 $\mu \mathrm{m}$ thick) were incubated for $30 \mathrm{~min}$ in $0.3 \%$ hydrogen peroxide in methanol to quench endogenous peroxidase activity. After washing three times with phosphate-buffered saline (PBS) for $10 \mathrm{~min}$ each, slides were incubated with preblocking serum (normal goat serum $1.5 \%$, bovine serum albumin $2 \%$, triton-X $0.1 \%$ ) for $1 \mathrm{~h}$ at room temperature. Primary antibody of FLT3 (Santa Cruz Biotechnology) was applied at a concentration of $5 \mu \mathrm{g} / \mathrm{mL}$ in preblocking solution and kept at $4{ }^{\circ} \mathrm{C}$ for overnight. After washing three times with PBS, tissue sections were incubated for 15 min each with biotinylated antimouse and antirabbit Ig and streptavidin-HRP (all Dako, Glostrup, Denmark) at room temperature. After washing $10 \mathrm{~min}$ with PBS, slides were rinsed in $0.5 \%$ Triton-X 100/PBS for $30 \mathrm{~s}$. Color developments were achieved by incubation with Liquid DAB+ (Dako). The slides were then counterstained with hematoxylin and mounted using Faramount Aqueous Mounting Medium (Dako).

\section{Results}

\section{Cloning of rat FLT3}

We aimed to clone rat homolog of FLT3 cDNA in three overlapping fragments (Part 1, Part 2, and Part 3) from thymus (Fig. 1a). However, cloning of part 1 , the most $5^{\prime}$ fragment, could not be accomplished using F1e and R1 primer pair. Therefore, a second forward primer, F1 that recognizes a sequence located approximately 35 base pairs downstream of the coding region was designed. All three fragments were amplified individually (Fig. 1b); sequencing of these fragments revealed a partial cDNA sequence for rat homolog of FLT3 gene (Fig. 2a). Alignment of this sequence with mouse FLT3 (NM010229) and human FLT3 (NM004119) by BCM Search Launcher: Multiple Sequence Alignments tool (Baylor College of Medicine) showed $90 \%$ homology with mouse and $81 \%$ homology with human sequences (Fig. 2b).

\section{Tissue specific expression of rat FLT3}

We analyzed the expression of FLT3 in different rat tissues at both the mRNA and the protein levels. Our results showed that FLT3 mRNA was expressed variably in the entire tissues examined (Fig. 3). In uterus, spleen, cerebellum and lungs, the expression of FLT3 was high, whereas in brain, ovary and skeletal muscle FLT3 level was found to be relatively low. In contrast to the presence of FLT3 mRNA in heart and kidney (Fig. 3), we did not detect any expression of FLT3 at the protein level in these tissues (Fig. 4a, first two lanes). Our Western blot experiments revealed the presence of FLT3 protein in other tissues (Fig. 4a).

\section{Expression of FLT3 mRNA during progenitor cell-dependent liver regeneration}

The primer efficiencies of FLT3 and CYC were 1.95 and 1.90, respectively. As these values did not differ greatly from each other and approximated the expected value, the $2^{-\Delta \Delta \mathrm{Ct}}$ formula was used in calculation of the fold differences among groups. Our real-time PCR results showed that FLT3 mRNA expression decreased at all time points in the $\mathrm{PH}$ groups compared to that of normal liver during progenitor cell-dependent liver regeneration (Fig. 5a). The expression of FLT3 also decreased in the SH groups when compared to normal liver although not to the extent observed in the $\mathrm{PH}$ groups, except at the $24 \mathrm{~h}$ after the operation. When we examined the expression in liver regeneration after $70 \%$ hepatectomy in rats without 2-AAF administration, we observed a similar pattern to the $\mathrm{PH}$ group, except at $2 \mathrm{~h}$ after $\mathrm{PH}$ (Fig. 5b). The difference between these two groups may reflect the effect of 2-AAF. 
(a)

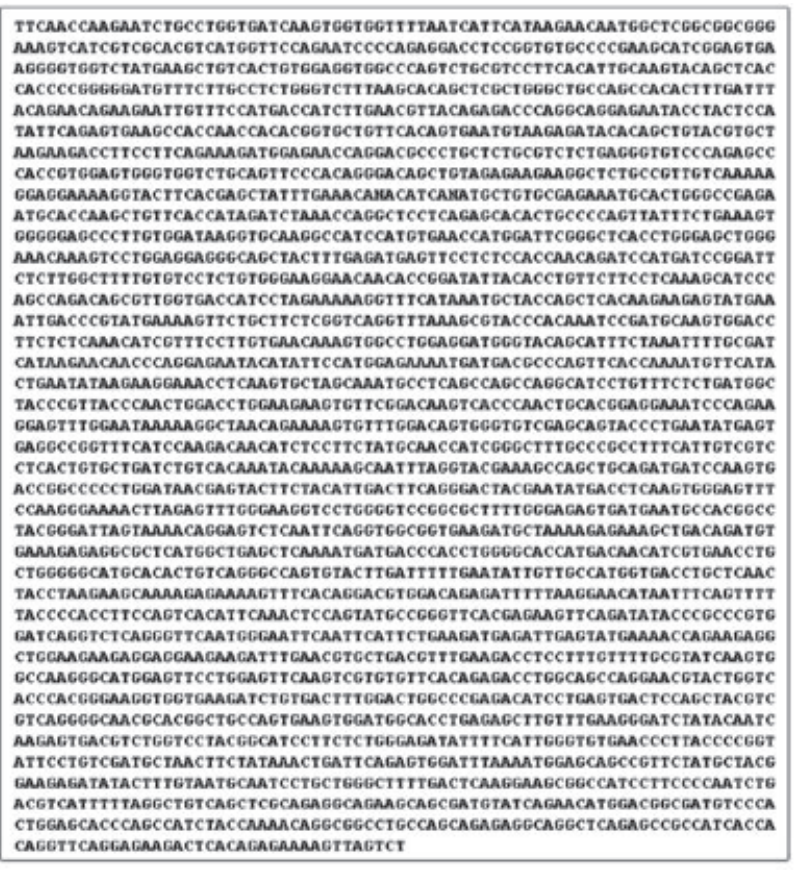

(b)

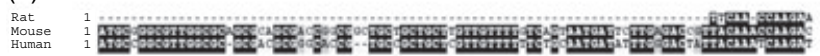
Rat
Mous
Human
98

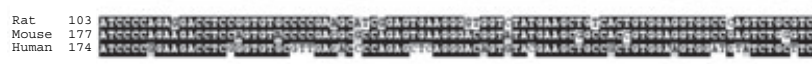

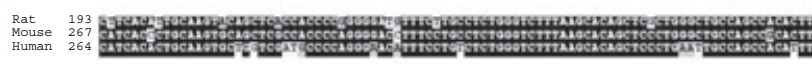

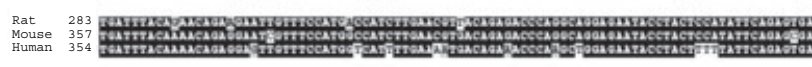

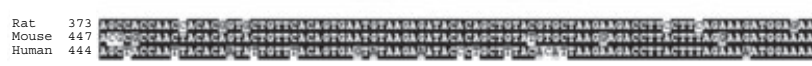
Rat
hus
Hunan
533
532

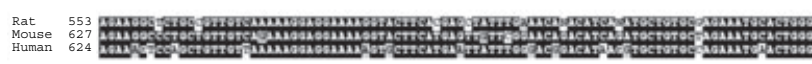

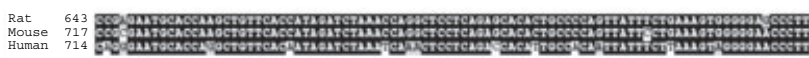

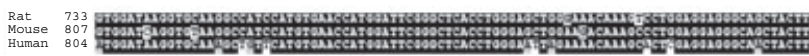

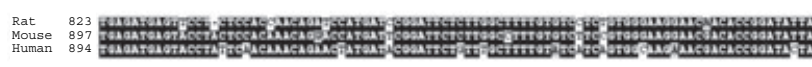

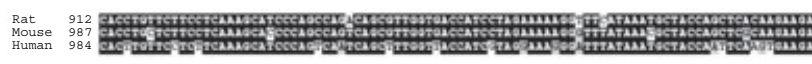

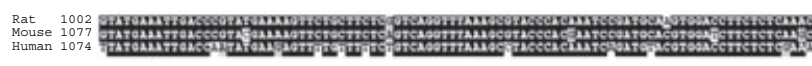

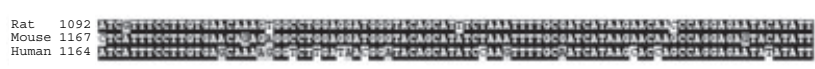

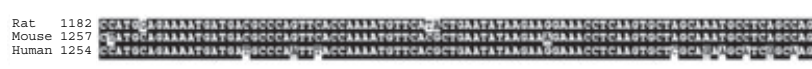

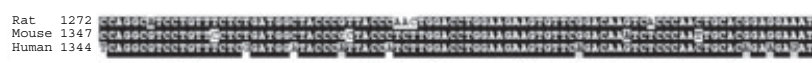

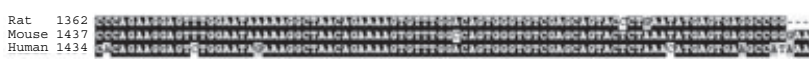

(b) continued

Rat 1449
Mouse 1527
Human 1524

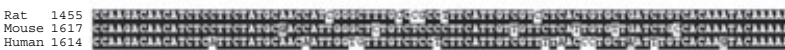
Rat 1545
Mouse 1700
Human 1704

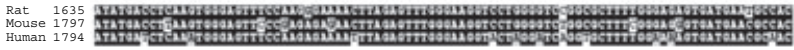

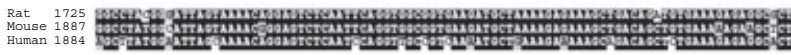

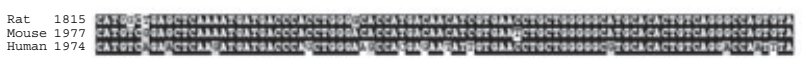

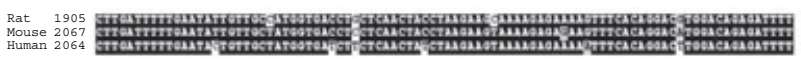

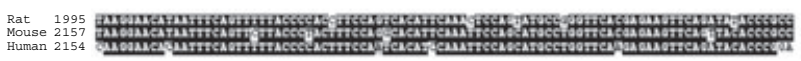

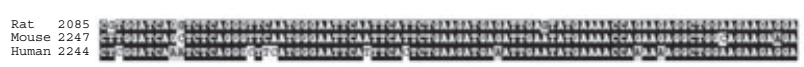
Rat 2175
Mouse 233
Human 233

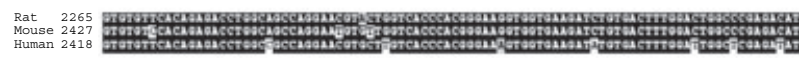
Rat 2355
Mouse 2517
Hunan 2508

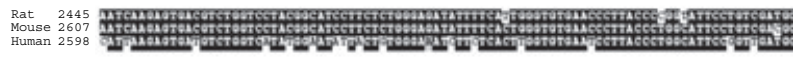

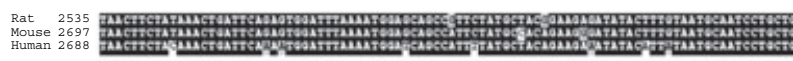

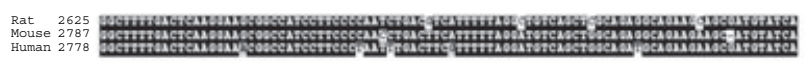

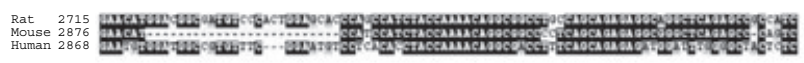

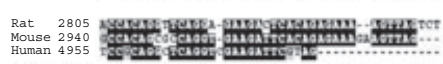

Figure 2 (a) Partial sequence of rat homolog of FLT3 cDNA. (b) Comparison of rat, mouse (NM 010229) and human (NM 004119$)$ FLT3 cDNAs. The regions that are conserved in all three species are shown in black blocks. 
Figure 3 Expression of (a) FLT3 and (b) CYC mRNA in rat tissues. $\mathrm{M}, 100 \mathrm{bp}$ DNA Ladder Plus; (-), negative control.
M - Thymus Liver Brain Uterus Spleen Ovary Tongue Heart Kidney Cerebel. Lung Muscle

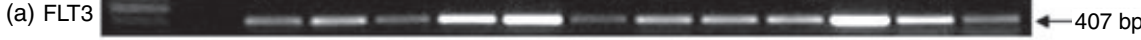

(b) $\mathrm{CYC}$

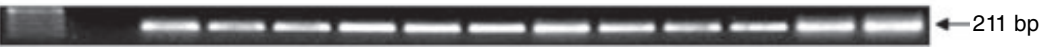

(a) Heart Kidney Thymus Liver Uterus Lung Spleen Ovary Brain Testicle

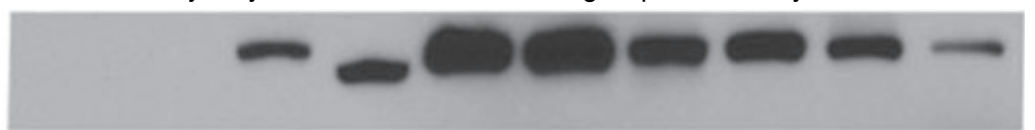

(b)

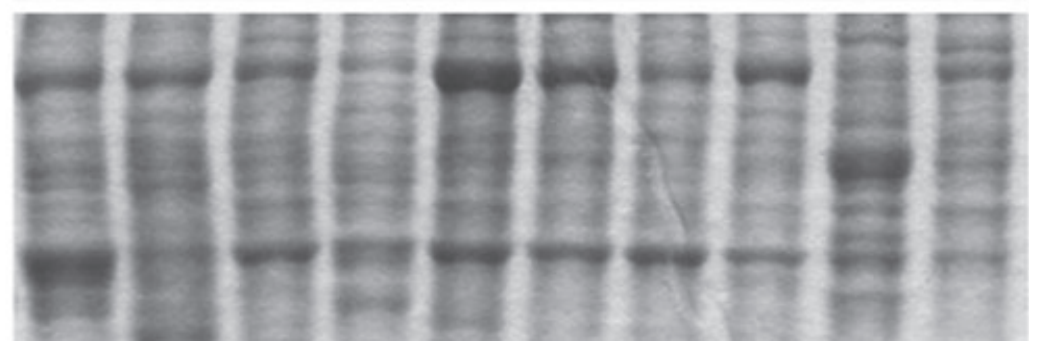

Figure 4 Expression of FLT3 protein in rat tissues by (a) Western blotting with anti-FLT3 antibody and (b) SDS-PAGE with Coomassie staining.

FLT3 protein in $\mathrm{PH}$ and SH groups (Fig. 7). In parallel with Western blot, FLT3 protein was detected in both PH (Fig. 7f-j) and $\mathrm{SH}$ groups (Fig. 7k-o) by immunohistochemistry. Interestingly, the cellular localization of FLT3 was different among our samples (Fig. 8). In the SH groups (Fig. 8c,d) and the early $\mathrm{PH}$ groups (Fig. 8a), FLT3 protein showed a membranous staining, but in the late $\mathrm{PH}$ groups the staining was mainly seen in the cytoplasm (Fig. 8b).

\section{Discussion}

From the work described in this article we were able to achieve the following: (i) cloning and characterization of rat FLT3 cDNA, which showed extremely high homology with mouse and to a lesser extent with human; (ii) possible explanation of the mechanism of FLT3 during progenitor-dependent liver regeneration.

Three different types of cells are believed to regenerate hepatocytes: hepatocytes, oval cells and bone marrow derived stem cells. ${ }^{23}$ Among these cell types, there has been debate on the role of bone marrow derived stem cells. These are multipotent cells and have a very long proliferation potential. However, they rarely constitute more than $1 \%$ of the total hepatocytes in humans, ${ }^{24}$ and their role in rodents is still controversial, if any. ${ }^{25}$ In contrast, the involvement of hepatocytes and oval cells during liver regeneration is well established. ${ }^{13}$ If the liver damage is less severe, mature hepatocytes respond rapidly to liver injury. ${ }^{24}$ Finally, oval cells are also the source of new hepatocytes, and these cells are activated when the liver damage is extensive and chronic, or if proliferation of hepatocytes is inhibited. Oval cell precursors located in the canal of Hering represent likely candidates for liver-repopulating stem cells, and can be considered a facultative liver stem cell. ${ }^{24,26,27}$

Oval cells express not only markers of the hepatocyte and bile duct lineage but also markers of hematopoietic stem cells such as FLT3. ${ }^{28,29}$ As FLT3 is a subclass III RTK, it is logical to assign a role to FLT3 during liver regeneration. However, its expression pattern during liver regeneration is not known. Therefore, we 


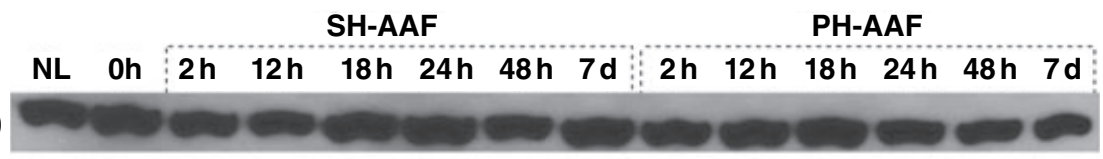

(b)

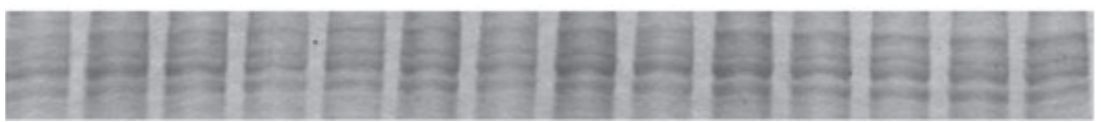

Figure 6 Expression of proteins extracted from 2-AAF-treated sham hepatectomy (SH) and partial hepatectomy (PH) groups by (a) Western blotting with anti-FLT3 antibody and (b) SDS-PAGE with Coomassie staining
$2 \mathrm{~h}$

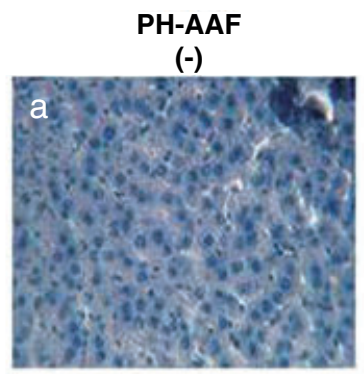

$12 \mathrm{~h}$

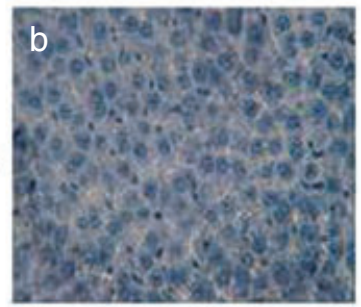

$18 \mathrm{~h}$

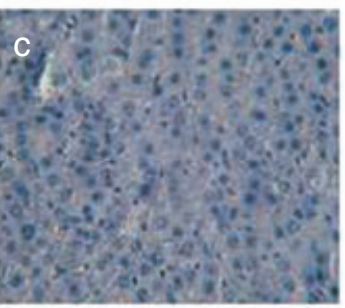

$24 \mathrm{~h}$

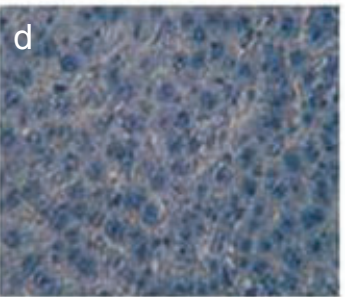

$7 d$

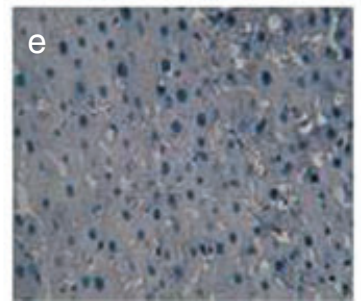

PH-AAF

FLT3
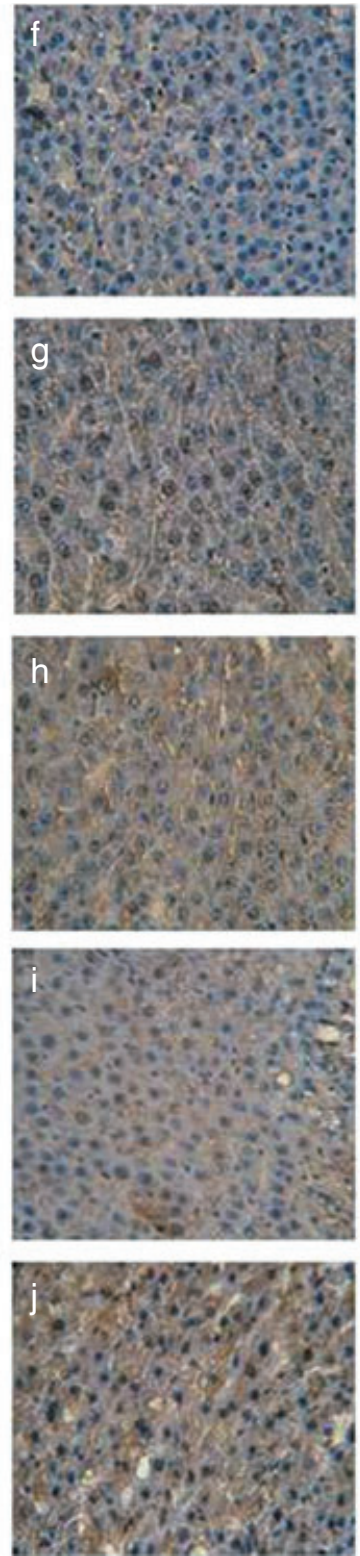

SH-AAF

FLT3
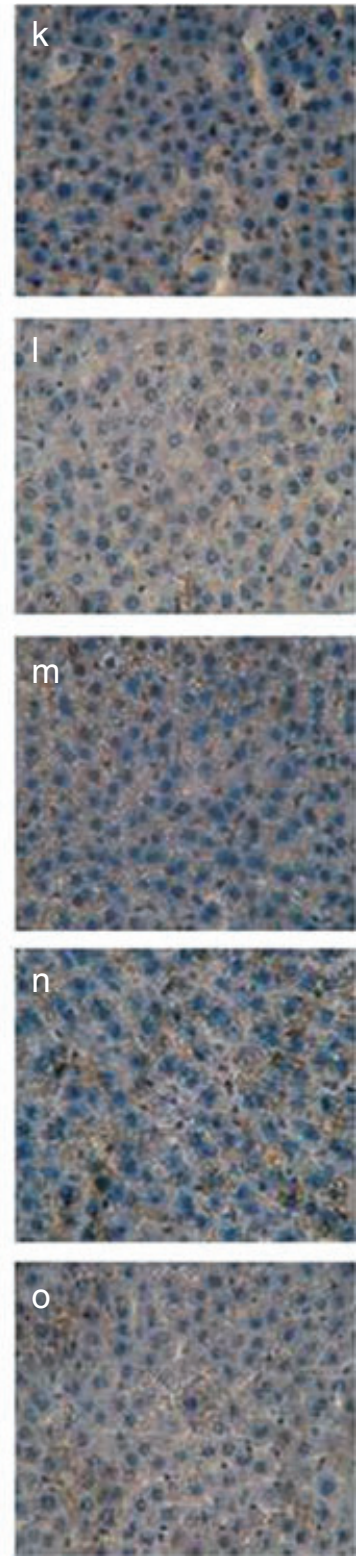

Figure 7 Immunohistochemistry of 2-AAFtreated sham hepatectomy (SH) and partial hepatectomy (PH) groups: (a-e) untreated (control) PH group, (f-j) PH group; and $(k-0)$ $\mathrm{SH}$ group. aimed to investigate the expression profile of FLT3 during progenitor cell-dependent rat liver regeneration, which was triggered by 2 -AAF-treatment in combination with $\mathrm{PH}$. Our results showed that there was a reduction at the mRNA level of FLT3 after PH. In both the PH and SH groups, the anesthetic used might have had an effect on the expression profile of liver cells. The reduction in the mRNA transcript level of FLT3 in the PH groups also may be related to the massive loss of cells. The observed pattern of FLT3 

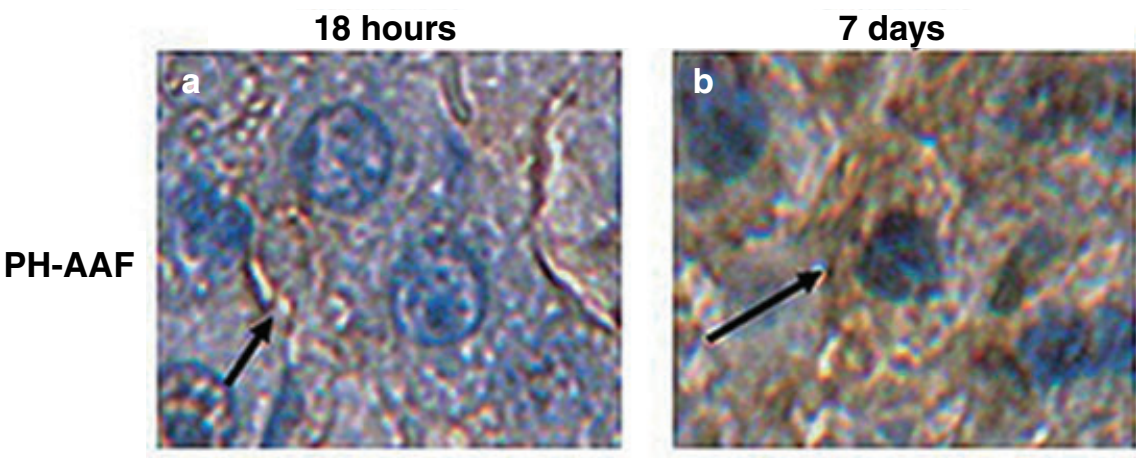

Figure 8 Cellular localization of FLT3 protein in $(\mathrm{a}, \mathrm{b})$ partial hepatectomy $(\mathrm{PH})$ and $(\mathrm{c}, \mathrm{d})$
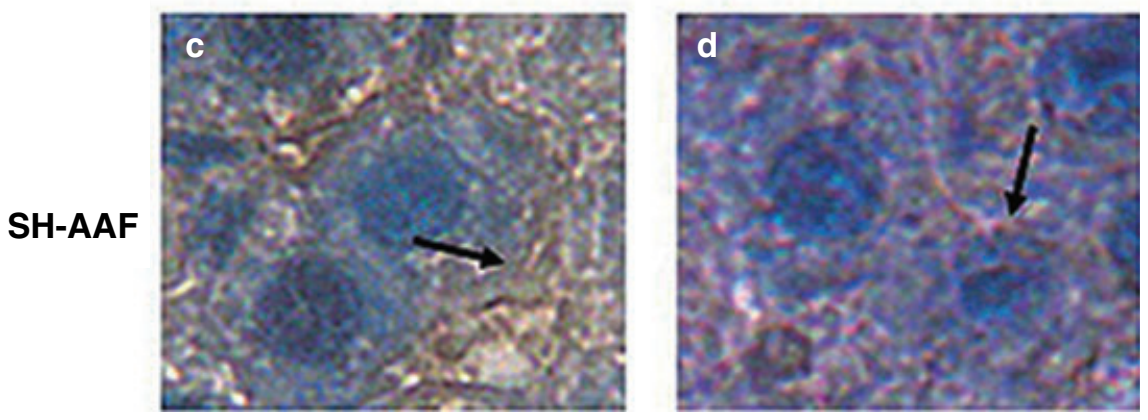
with black arrows.

expression and lack of a tight correlation between the mRNA and protein levels of FLT3 suggests that an increase in FLT3 expression may not always be a prominent feature of liver regeneration. In addition, the FLT3 protein level was almost equal in all groups.

Our findings indicated that post-translational mechanisms, such as translocation of FLT3 between cellular compartments, might also play important roles. Therefore, we performed immunohistochemistry experiments in order to examine the localization of FLT3 protein in different experimental groups. Our results revealed that in all 2-AAF-treated $\mathrm{SH}$ groups and in early groups of 2-AAF-treated PH samples ( $2 \mathrm{~h}, 12 \mathrm{~h}$ and $18 \mathrm{~h}$ ), FLT3 expression was seen exclusively on the plasma membrane. Interestingly, in later AAF-treated PH groups, especially in the 7 days after $\mathrm{PH}$ group, there was strong cytoplasmic staining. The change in the cellular localization of the FLT3 during early and late stages of liver regeneration strongly suggests alterations in the activation status of the FLT3 receptor. Under normal conditions (normal liver and $\mathrm{SH}$ groups), FLT3 resides in the plasma membrane in an inactive monomeric form. However, when liver injury occurs and the liver undergoes a regeneration process, FLT3 is activated and internalized in order to relay signals for proliferative events. Activation and internalization of receptors ultimately results in the degradation of receptors as shown previously. ${ }^{17}$ Therefore, the cytoplasmic staining of FLT3 protein in late 2-AAF-treated PH groups may reflect the presence of internalized FLT3 receptors. Western blotting results of the $24 \mathrm{~h}$ and 7 days $\mathrm{PH}$ groups in which FLT3 protein levels were relatively lower support this model of increased FLT3 receptor degradation.

Taking all our findings together, a likely scenario would be as follows: under normal conditions (normal liver and SH groups), FLT3 is expressed on the plasma membrane in its monomeric inactive form. The situation is also the same in the early $\mathrm{PH}$ groups. However, in the late $\mathrm{PH}$ groups, in addition to other factors, FLT3 is activated and internalized in order to potentiate cellular proliferation.

\section{Acknowledgments}

This study was supported by Tubitak (TBAG-2284) and a Bilkent University Research Grant.

\section{References}

1 Sell S. Is there a liver stem cell? Cancer Res. 1990; 50: 3811-15.

2 Fausto N. Hepatology: A Textbook of Liver Disease, 2nd edn. Philadelphia: Saunders, 1990; 49-64.

3 Alison M. Liver stem cells: a two compartment system. Curr. Opin. Cell Biol. 1998; 10: 710-15.

4 Factor VM, Radaeva SA, Thorgeirsson SS. Origin and fate of oval cells in dipin-induced hepatocarcinogenesis in the mouse. Am. J. Pathol. 1994; 145: 409-22.

5 Vessey CJ, de la Hall PM. Hepatic stem cells: a review. Pathology 2001; 33: 130-41.

6 Kruglov EA, Jain D, Dranoff JA. Isolation of primary rat liver fibroblasts. J Investig. Med. 2002; 50: 179-84.

7 Sirica AE, Mathis GA, Sano N, Elmore LW. Isolation, culture, and transplantation of intrahepatic biliary epithelial cells and oval cells. Pathobiology 1990; 58: 44-64.

8 Sirica AE. Ductular hepatocytes. Histol. Histopathol. 1995; 10: 433-56.

9 Alison M, Golding M, Lalani el-N, Sarraf C. Wound healing in the liver with particular reference to stem cells. Philos. Trans. R. Soc. London B Biol. Sci. 1998; 353: 877-94.

10 Paku S, Schnur J, Nagy P, Thorgeirsson SS. Origin and structural evolution of the early proliferating oval cells in rat liver. Am. $J$. Pathol. 2001; 158: 1313-23. 
11 Mitaka T. Hepatic stem cells: from bone marrow cells to hepatocytes. Biochem. Biophys. Res. Commun. 2001; 281: 1-5.

12 Matsusaka S, Tsujimura T, Toyosaka A et al. Role of c-kit receptor tyrosine kinase in development of oval cells in the rat 2-acetylaminofluorene/partial hepatectomy model. Hepatology 1999; 29: 670-6.

13 Fausto N. Liver regeneration and repair: hepatocytes, progenitor cells, and stem cells. Hepatology 2004; 39: 1477-87.

14 Peterson BE. Hepatic 'stem' cells: coming full circle. Blood Cells Mol. Dis. 2001; 27: 590-600.

15 Agnes F, Shamoon B, Dina C, Rosnet O, Birnbaum D, Galibert F. Genomic structure of the downstream part of the human FLT3 gene: exon/intron structure conservation among genes encoding receptor tyrosine kinases (RTK) of subclass III. Gene 1994; 145: 283-8.

16 Stirewalt DL, Radich JP. The role of FLT3 in haematopoietic malignancies. Nat. Rev. Cancer 2003; 3: 650-65.

17 Turner AM, Lin NL, Issarachai S, Lyman SD, Broudy VC. FLT3 receptor expression on the surface of normal and malignant human haematopoietic cells. Blood 1996; 88: 3383-90.

18 Weiss A, Schlessinger J. Switching signals on or off by receptor dimerization. Cell 1998; 94: 277-80.

19 Hong SH, Gang EJ, Jeong JA et al. In vitro differentiation of human umbilical cord blood-derived mesenchymal stem cells into hepatocyte-like cells. Biochem. Biophys. Res. Commun. 2005; 330: 1153-61.

20 Akcali KC, Dalgic A, Ucar A, Haj KB, Guvenc D. Expression of bcl-2 gene family during resection induced liver regeneration: comparison between hepatectomized and sham groups. World $J$ Gastroenterol. 2004; 10: 279-83.
21 Wang X, Parsson H, Anderson R, Soltesz V, Johansson K, Bengmark S. Bacterial translocation, intestinal ultrastructure and cell membrane permeability early after major liver resection in the rat. Br. J. Surg. 1994; 81: 579-84.

22 Livak KJ, Schmittgen TD. Analysis of relative gene expression data using real-time quantitative PCR and the $2^{-\Delta \Delta \mathrm{Ct}}$ method. Methods 2001; 25: 402-8.

23 Grompe M, Finegold MJ. Liver stem cells. In: Marshak DR, Gardner RL, Gottlieb D, eds. Stem Cell Biology. Cold Spring Harbor, NY: Cold Spring Harbor Laboratory Press, 2001; 455-97.

24 Fausto N, Riehle KJ. Mechanisms of liver regeneration and their clinical implications. J. Hepatobiliary Pancreat. Surg. 2005; 12: 181-9.

25 Fujii H, Hirose T, Oe S et al. Contribution of bone marrow cells to liver regeneration after partial hepatectomy in mice. J. Hepatol. 2002; 36: 653-9.

26 Fausto N, Lemire JM, Shiojiri N. Cell lineages in hepatic development and the identification of progenitor cells in normal and injured liver. Proc. Soc. Exp. Biol. Med. 1993; 204: 237-41.

27 Theise ND, Saxena R, Portmann BC et al. The canals of Hering and hepatic stem cells in humans. Hepatology 1999; 30: 1425-33.

28 Petersen BE, Grossbard B, Hatch H, Pi L, Deng J, Scott EW. Mouse A6-positive hepatic oval cells also express several hematopoietic stem cell markers. Hepatology 2003; 37: 632-40.

29 Zhang Y, Bai XF, Huang CX. Hepatic stem cells: existence and origin. World J. Gastroenterol. 2003; 9: 201-4. 